\title{
A New Animal Model of Hemolytic Hyperbilirubinemia-Induced Bilirubin Encephalopathy (Kernicterus)
}

\author{
ANN C. RICE AND STEVEN M. SHAPIRO \\ Department of Neurology [A.C.R., S.M.S.], Departments of Pediatrics, Physiology, Otolaryngology-Head and Neck Surgery [S.M.S.], \\ Virginia Commonwealth University, Richmond, Virginia, 23298
}

\begin{abstract}
Neonatal hyperbilirubinemia can cause bilirubin encephalopathy (kernicterus). Spontaneously jaundiced (jj) Gunn rats treated with sulfonamide (sulfa) to displace bilirubin from serum albumin, develop bilirubin encephalopathy and abnormal brainstem auditory evoked potentials (BAEPs) comparable with human newborns. We hypothesized phenylhydrazine (PHZ)-induced hemolysis would significantly elevate total plasma bilirubin (TB) in jj Gunn rat pups and produce BAEP abnormalities similar to those observed after sulfa. PHZ $0,25,50$, or $75 \mathrm{mg} / \mathrm{kg}$ was administered intraperitonealy to 15 -d-old jjs. An initial TB was recorded in each animal, and a second recorded 1-4 d postinjection to generate a dose-response curve. After PHZ $75 \mathrm{mg} / \mathrm{kg}$, TB peaked at about $30 \mathrm{mg} / \mathrm{dL}$ at $48-72 \mathrm{~h}$. A second group of jjs injected with PHZ $(0,25,50$, or $75 \mathrm{mg} / \mathrm{kg})$ and nonjaundiced controls given PHZ $75 \mathrm{mg} / \mathrm{kg}$ had HCT and TB at baseline, and HCT, TB, and BAEPs recorded at $48 \mathrm{~h}$. BAEP wave II and III amplitudes decreased, and I-II and I-III interwave intervals increased indicating abnormal central (brainstem) auditory function. PHZ-induced hemolysis in jaundiced Gunn rat pups produces sufficiently elevated TB levels to produce bilirubin encephalopathy. This new model may be a more clinically relevant experimental model of kernicterus- and bilirubin-induced neurologic disorders. (Pediatr Res 64: 265-269, 2008)
\end{abstract}

$\mathrm{E}^{\mathrm{x}}$ xcessive hyperbilirubinemia in newborns may produce acute bilirubin encephalopathy, kernicterus- and bilirubin- induced neurologic disorders (BIND). Neonatal hyperbilirubinemia has many causes but, ultimately, results from an imbalance between bilirubin production and elimination (1). Newborns have an impaired ability to eliminate bilirubin because of immaturity of UDP-glucuronosyl transferase (UGT), an enzyme that conjugates a glucuronide group to bilirubin, rendering it more water soluble and more easily excretable $(2,3)$. Hemolysis, by increasing free $\mathrm{Hb}$, which is then metabolized to bilirubin, is a frequent cause of hyperbilirubinemia because of increased production in human neonates.

The homozygous recessive jaundiced (jj) Gunn rat pup is the classic animal model of bilirubin encephalopathy and kernicterus (4). The jj Gunn rat lacks functional UGT, has impaired elimination of bilirubin, and is jaundiced throughout its lifespan (5). The jj Gunn rat reliably develops acute central nervous system (CNS) dysfunction and kernicterus when

Received January 2, 2008; accepted April 18, 2008.

Correspondence: Steven M. Shapiro, M.D., P.O. Box 980211, Richmond, VA 232980211; e-mail: sshapiro@vcu.edu

This research was supported by N.I.H. R01 grants DC000369 and NS04715 (to S.M.S.). given a long-acting sulfonamide, sulfadimethoxine (sulfa), to displace bilirubin from blood into tissues including brain (6-8). Acute bilirubin-induced CNS dysfunction can be measured in sulfa-treated jjs with brainstem auditory evoked potentials (BAEPs) $(8-10)$.

Although useful to understand human disease, there are two problems with the jj sulfa Gunn rat model. First, total plasma bilirubin (TB) does not reflect CNS exposure when sulfa is given to displace bilirubin from blood into tissue and CNS. Second, our jj-sulfa model differs from the common clinical situation in that bilirubin-albumin displacers, initially reported as a cause of "low-bilirubin kernicterus" in 1956 (11), and more recently in an outbreak in a nursery in the 1980s (12), rarely cause kernicterus currently. We hypothesized that hemolysis would raise TB levels high enough to produce bilirubin encephalopathy in jj Gunn rats, and this model would more closely mimic the common condition of the hyperbilirubinemic human newborn.

Our objective was to create a new model of hemolysisinduced acute bilirubin encephalopathy using phenylhydrazine (PHZ), which lyses red blood cells (13). We administered PHZ to jj Gunn rat pups who, similar to human neonates, have impaired conjugation of bilirubin. We hypothesized that we could induce excessively high bilirubin levels, which would lead to BAEP abnormalities indicating auditory dysfunction.

\section{METHODS}

All procedures were approved by the Institutional Animal Care and Use Committee of Virginia Commonwealth University, and all efforts were made to minimize pain and stress and to reduce the number of animals required. Spontaneously jaundiced homozygous recessive (jj) Gunn rat pups and heterozygous nonjaundiced $(\mathrm{Nj})$ littermates were obtained from our in-house breeding colony. Experiments were performed on 15- to 16-d-old animals, which corresponds to the natural bilirubin peak in this strain. PHZ, dissolved in saline, was purchased from Sigma Chemical Co., Aldrich (St. Louis, MO).

TB levels. Blood samples were collected via a cheek puncture into an 85 $\mu \mathrm{L}$ heparinized hematocrit tube. Samples were centrifuged and the hematocrit (HCT) was measured. The plasma was collected and analyzed for plasma bilirubin level using a Leica Unistat Bilirubinometer (Reichert, Inc., Depew, NY). This requires approximately $25 \mu \mathrm{L}$ of plasma/analysis, thus $50-80 \mu \mathrm{L}$ of blood were taken for each measurement. Hematocrit and TB were recorded

Abbreviations: BAEPs, brainstem auditory evoked potentials; BIND, bilirubin-induced neurological disorders; HCT, hematocrit; IWI, interwave interval; Jj, homozygous jaundiced Gunn rat; $\mathbf{N j}$, heterozygous nonjaundiced Gunn rat; PHZ, phenylhydrazine; Sulfa, sulfadimethoxine; TB, total plasma bilirubin 
for each blood sample. Because of the small size of the animals, a maximum of two blood samples were drawn from each animal.

PHZ dose and time course curve. A total of 150 animals from 44 litters were used to generate the PHZ dose and time-response curve. Animals were randomly assigned to $\mathrm{PHZ}$ dose and time of obtaining the second TB. After baseline TB and HCT measurements, animals were injected with PHZ 25, 50 or $75 \mathrm{mg} / \mathrm{kg}$ intraperitoneal, or saline (PHZ $0 \mathrm{mg} / \mathrm{kg}$ ), and a second TB and HCT were measured at the designated time.

Brainstem auditory evoked potentials (BAEPs). In $40 \mathrm{jj}$ and $10 \mathrm{Nj}$ pups from nine different litters, baseline TB and HCT were performed at 15 or $16 \mathrm{~d}$ of age, and TB, HCT, and BAEPs were recorded $48 \mathrm{~h}$ after injection of PHZ 0 (saline), 25,50 , or $75 \mathrm{mg} / \mathrm{kg}$ intraperitoneal in jjs and $75 \mathrm{mg} / \mathrm{kg} \mathrm{PHZ}$ intraperitoneal in Njs. At $48 \mathrm{~h}$ after PHZ, blood for TB and HCT was obtained, and animals were anesthetized with an intramuscular injection of 60 $\mathrm{mg} / \mathrm{kg}$ ketamine and $6 \mathrm{mg} / \mathrm{kg}$ acepromazine. BAEPs were recorded using a Nicolet Spirit 2000 evoked potential system (Biosys, Inc., Madison, WI). The left ear was occluded with petrolatum, and BAEPs were obtained to monaural $100 \mu$ s duration rarefaction clicks delivered at 31.7/s to the right ear through a Sony Walkman 4LIS headphone speaker (14). The sound intensity was nominally set at $70 \mathrm{~dB}$, which we calibrated biologically, and corresponded to a level of $62 \mathrm{~dB}$ above a normal Gunn rat pup BAEP threshold level as described previously (15). Surface electrical activity was recorded from 13-mm platinum needle electrodes inserted subcutaneously on the scalp over the vertex and behind the left and right mastoid bullae with a ground electrode in the flank. Rectal temperature was controlled at $37.0 \pm 0.1^{\circ} \mathrm{C}$ using a heating blanket and red heat lamp and stabilized for a minimum of $5 \mathrm{~min}$ before and during the recording. Two channel BAEP recordings were obtained from the contralateral to the ipsilateral mastoid ("horizontal") and the vertex to the ipsilateral mastoid ("vertical") electrode pairs, filtered from 30 to $3000 \mathrm{~Hz}$. As there were no significant differences between the two orientations, only data from the horizontal montage are presented. The vertical channel was used to help identify uncertain peaks. Each individual BAEP was the averaged response to 2000 stimuli, and three or more replicated responses were obtained for each animal. The individual BAEP replications were summed, and the peak latencies and peak-to-trough amplitudes of BAEP wave I, II, and III were scored using a cursor. Latencies were subtracted to obtain interwave intervals (IWIs).

Statistics. Statistical analyses to assess the main effects of DOSE (4 levels-0, 25, 50, and $75 \mathrm{mg} / \mathrm{kg}$ ), DAY after PHZ injection (4 levels, days 1 though 4), and the DOSE * DAY interaction of TB and HCT were performed using two-factor analysis of variance (ANOVA), and post hoc group comparisons were done with Tukey HSD post hoc tests (SPSS, Chicago: SPSS, Inc.). To assess the effects on BAEPs $48 \mathrm{~h}$ after PHZ, one-way ANOVA with post hoc Tukey HSD comparisons were performed on the six BAEP wave variables used to assess bilirubin neurotoxicity in this model- the amplitudes of waves I, II, and III, the latency of I, and the I-II and I-III IWIs (15). To avoid spurious false positive results from multiple subgroup analyses, i.e. ANOVAs of six different BAEP dependent variables, an overall, experimentwise $p$ value of 0.05 was divided by 6 to give an individual criterion $p$ value of 0.00833 for each ANOVA $(16,17)$.

\section{RESULTS}

Dose and time response curves for TB and HCT were performed in 15-d-old jj Gunn rat pups given doses from 0 (saline control) to $75 \mathrm{mg} / \mathrm{kg}$ PHZ to determine when plasma TB reached peak levels (Fig. 1). Baseline TB of $10.8 \pm 1.5$ $\mathrm{mg} / \mathrm{dL}$ (mean $\pm \mathrm{SD}, n=150$ ) rose and peaked $48 \mathrm{~h}$ after PHZ administration in all groups (Fig. 1A). Because of high mortality, the $75 \mathrm{mg} / \mathrm{kg}$ dose experiment was terminated at $72 \mathrm{~h}$. By ANOVA there were highly significant main effects of DOSE $\left(p<10^{-9}\right)$, DAY $(p<0.002)$, and DOSE $*$ DAY $(p<$ 0.00003 ) on the change in TB calculated by subtracting the baseline from the second TB value. All PHZ doses produced an increase in TB versus the $0 \mathrm{mg} / \mathrm{kg}$ (saline) group ( $p<$ $10^{-9}$, Tukey HSD). At $75 \mathrm{mg} / \mathrm{kg}$ PHZ, mean plasma TB levels peaked at $27.3 \pm 5.1 \mathrm{mg} / \mathrm{dL}$, and peaked as high as $34 \mathrm{mg} / \mathrm{dL}$ in one animal after a baseline of $11.2 \mathrm{mg} / \mathrm{dL}$, higher than we have ever previously observed in a Gunn rat. We did not perform systematic clinical evaluations on these rats, but anecdotally noted abnormal muscle tone (dystonia) in upper
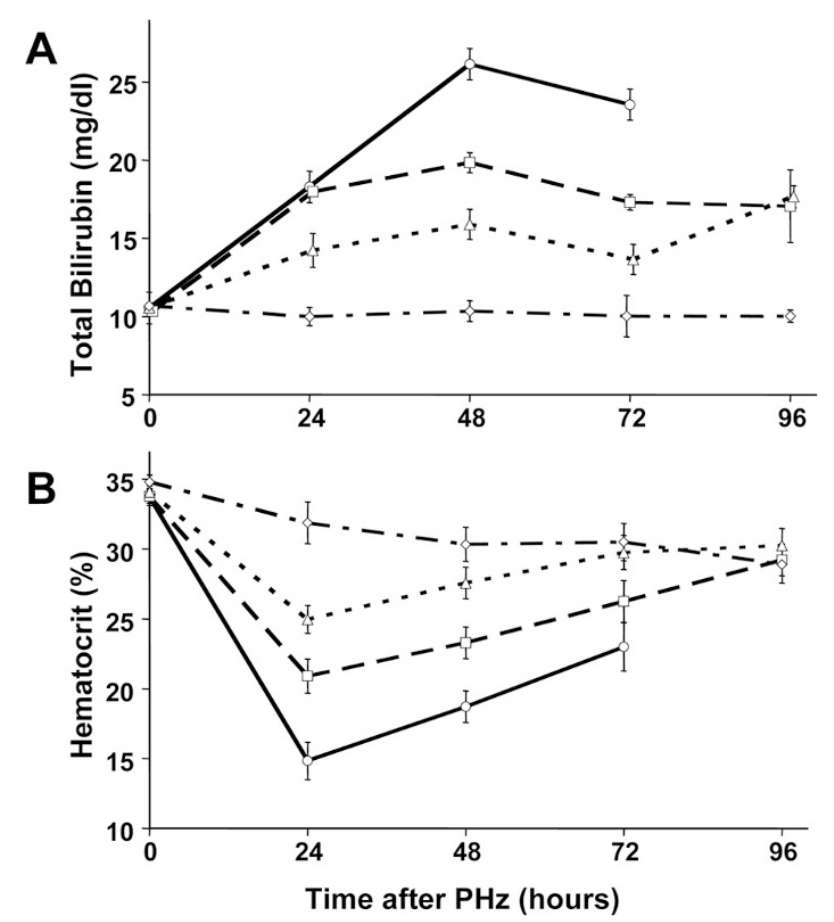

Figure 1. Total bilirubin (TB) $(A)$ and $\mathrm{HCT}(B) 24-96 \mathrm{~h}$ after intraperitoneal injection of PHZ $0,25,50$, or $75 \mathrm{mg} / \mathrm{kg}$ into 16 -d-old jj Gunn rat pups. TB peaked at $26.2 \pm 4.4 \mathrm{mg} / \mathrm{dL}(451 \pm 75 \mu \mathrm{M}) 48 \mathrm{~h}$ after PHZ in the group given $75 \mathrm{mg} / \mathrm{kg}$, whereas HCT reached a nadir at $24 \mathrm{~h}$. Values are mean \pm SEM; PHZ 75 mg/kg jj ( $\bigcirc$, solid line); PHZ 50 mg/kg jj ( $\square$, dashed line); PHZ 25 $\mathrm{mg} / \mathrm{kg} \mathrm{jj}$ ( $\triangle$, dotted line); and PHZ $0 \mathrm{mg} / \mathrm{kg}$ (saline) jj ( $\diamond$, dash and dot line).

and lower extremities of many of the rats with elevated TB levels.

HCT was determined to assess the amount of PHZ-induced hemolysis; HCT values were lowest $24 \mathrm{~h}$ after PHZ, and then rose gradually (Fig. 1B). There were significant main effects of DOSE, DAY, and DOSE * DAY on change in HCT (twofactor ANOVA, all $p<0.00001)$. HCT decreased $24 \mathrm{~h}$ after PHZ 25, 50, and $75 \mathrm{mg} / \mathrm{kg}$ versus the $0 \mathrm{mg} / \mathrm{kg}$ (saline) group $(p=0.017,0.0003$, and $<0.000001$, respectively, Tukey HSD).

BAEPs were performed $48 \mathrm{~h}$ after PHZ injection in a separate group of 50 animals. The physiologic parameters of the group of animals that had BAEPs recorded at $48 \mathrm{~h}$ are depicted in Table 1. Initial weights, TBs and HCTs were not significantly different between groups, except for the normal $\mathrm{TB}$ levels in the $\mathrm{Nj}$ group. TB increased and $\mathrm{HCT}$ dropped significantly in comparison with PHZ $0 \mathrm{mg} / \mathrm{kg}$ jj controls for the 50 and $75 \mathrm{mg} / \mathrm{kg}$ PHZ dose jj groups (ANOVA with Tukey HSD $p<0.05$ ), but not the PHZ $25 \mathrm{mg} / \mathrm{kg}$ jj group, whose values were intermediate but not significantly different from controls. The $75 \mathrm{mg} / \mathrm{kg}$ PHZ jj group had no weight gain at $48 \mathrm{~h}$, which was significantly different from the $0 \mathrm{mg} / \mathrm{kg}$ $\mathrm{PHZ} \mathrm{jj}$ and $75 \mathrm{mg} / \mathrm{kg}$ PHZ $\mathrm{Nj}$ control groups $(p<0.05)$ in these growing pups. There were no significant differences in HCT between $\mathrm{Nj}$ and $\mathrm{jj}$ animals given $75 \mathrm{mg} / \mathrm{kg}$ PHZ. In the $\mathrm{Nj} 75 \mathrm{mg} / \mathrm{kg}$ group, TB rose significantly but to a much lower level than in the jjs.

Figure 2 depicts representative BAEP waves obtained from a typical jj control animal (upper tracing) and from two 
Table 1. Physiological parameters (mean \pm standard deviation) of weight (Wt), total bilirubin (TB), and hematocrit (HCT) values in jaundiced (jj) and nonjaundiced (Nj) rat pups before and $48 \mathrm{~h}$ after phenylhydrazine (PHZ) injection in animals whose brainstem auditory evoked potentials (BAEPs) were recorded at $48 \mathrm{~h}$

\begin{tabular}{ccrcccccc}
\hline Geno-type & PHZ dose & \multicolumn{1}{c}{$n$} & Initial Wt $(\mathrm{g})$ & 48-h Wt $(\mathrm{g})$ & Initial TB $(\mathrm{mg} / \mathrm{dL})$ & 48-h TB $(\mathrm{mg} / \mathrm{dL})$ & Initial HCT $(\%)$ & 48-h HCT $(\%)$ \\
\hline $\mathrm{jj}$ & 75 & 13 & $25.2 \pm 3.5$ & $24.4 \pm 3.3^{* \dagger}$ & $11.4 \pm 2.1 \dagger$ & $23.6 \pm 6.9^{* \dagger}$ & $35.2 \pm 3.4$ & $22.9 \pm 4.7^{*}$ \\
$\mathrm{jj}$ & 50 & 8 & $28.1 \pm 4.6$ & $29.2 \pm 4.1$ & $10.5 \pm 1.1 \dagger$ & $20.4 \pm 4.0^{* \dagger}$ & $32.9 \pm 2.2$ & $23.1 \pm 2.1^{*}$ \\
$\mathrm{jj}$ & 25 & 6 & $25.5 \pm 2.2$ & $28.3 \pm 2.1$ & $10.1 \pm 1.4 \dagger$ & $14.2 \pm 2.9 \dagger$ & $33.3 \pm 3.6$ & $28.0 \pm 2.6 \dagger$ \\
$\mathrm{jj}$ & 0 & 13 & $25.6 \pm 3.3$ & $29.2 \pm 4.3$ & $11.0 \pm 1.4 \dagger$ & $10.9 \pm 1.7 \dagger$ & $35.5 \pm 3.5$ & $32.7 \pm 3.7^{*} \dagger$ \\
$\mathrm{Nj}$ & 75 & 10 & $28.6 \pm 4.7$ & $30.6 \pm 4.9$ & $0.0 \pm 0.0^{*}$ & $1.5 \pm 0.6^{*}$ & $36.3 \pm 2.3$ & $21.1 \pm 3.6^{*}$ \\
\hline
\end{tabular}

PHZ dose is $\mathrm{mg} / \mathrm{kg}$ of body weight; $n=$ no. animals per group.

$* p<0.05$ vs. jj PHZ $0 \mathrm{mg} / \mathrm{kg}$ (jj saline) control group.

$\dagger p<0.05$ vs. Nj PHZ $75 \mathrm{mg} / \mathrm{kg}$ control group.

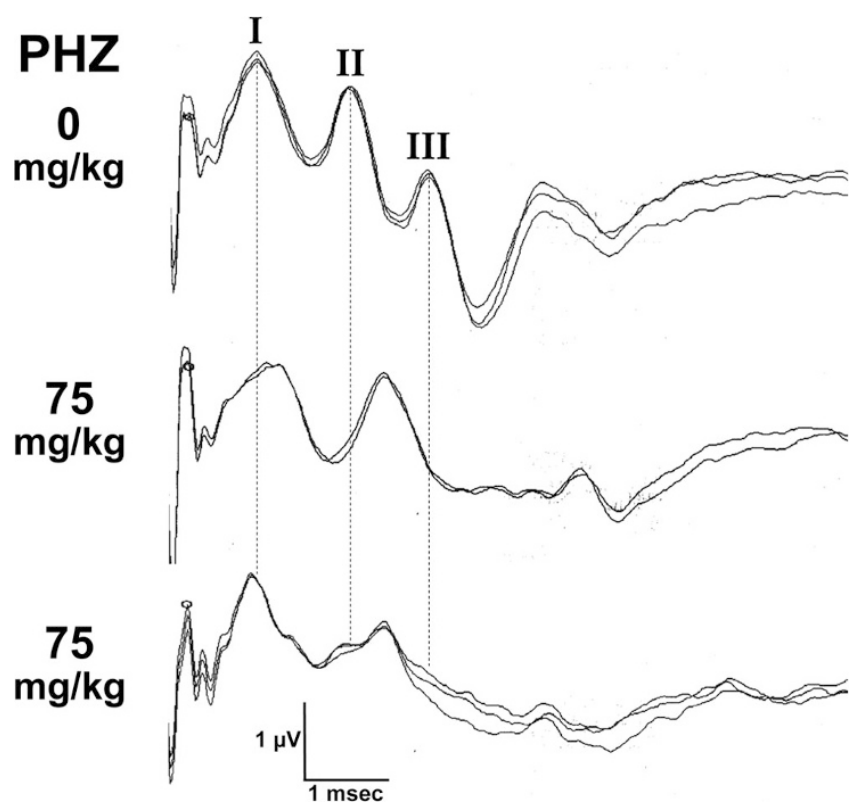

Figure 2. Representative BAEP waveforms in jj Gunn rats $48 \mathrm{~h}$ after PHZ in one control $(0 \mathrm{mg} / \mathrm{kg})$ and two experimental animals $(75 \mathrm{mg} / \mathrm{kg})$. Each BAEP is recorded and displayed in two or three replications. Note the increased latency and decreased amplitudes of waves II and III, corresponding to waves III and V, respectively, in humans. When wave III is absent, as in the two PHZ $75 \mathrm{mg} / \mathrm{kg}$ animals shown, amplitude is scored as $0 \mu \mathrm{V}$, and the latency and the I-III are not scored.

different experimental jj animals given PHZ $75 \mathrm{mg} / \mathrm{kg}$ (lower two tracings). One-way ANOVA showed overall significant differences between treatment groups for I-II and I-III IWIs, and the amplitude of waves I, II, and III ( $p \leq 0.001)$. Post hoc Tukey HSD analyses showed significant differences $(p<$ 0.00833 ) between the PHZ $75 \mathrm{mg} / \mathrm{kg}$ jj group and $\mathrm{jj}$ saline and/or PHZ $75 \mathrm{mg} / \mathrm{kg} \mathrm{Nj}$ control groups for all these variables except wave I (Fig. 3). The PHZ $75 \mathrm{mg} / \mathrm{kg}$ jj animals developed the most profound BAEP changes, while the changes in jjs administered lower doses (50 and $25 \mathrm{mg} / \mathrm{kg}$ ) were intermediate (Fig. 3).

\section{DISCUSSION}

There are relatively few useful animal models of kernicterus and BIND because of the difficulties of producing neurotoxicity by administering bilirubin to normal animals. Bilirubin is relatively insoluble in polar solvents at normal $\mathrm{pH}$, and normal animals are so efficient at conjugating and eliminating bilirubin that giving enough bilirubin to produce neu-
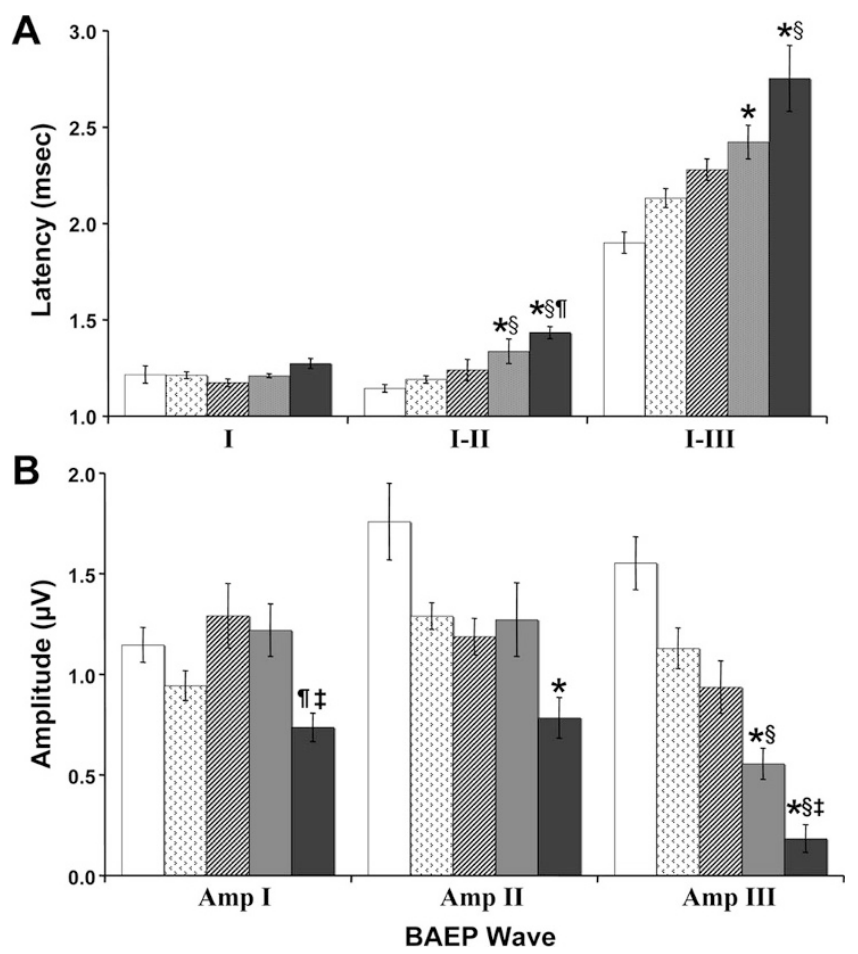

Figure 3. BAEP mean latencies $(A)$ and amplitudes $(B) 48 \mathrm{~h}$ after PHZ 75 $\mathrm{mg} / \mathrm{kg}$ intraperitoneal in nonjaundiced $(\mathrm{Nj})$ controls $(n=10$, white columns), or in jaundiced (jj) Gunn rats given PHZ $0 \mathrm{mg} / \mathrm{kg}(n=13$, stippled columns), $25 \mathrm{mg} / \mathrm{kg}$ ( $n=6$, diagonal columns), 50 ( $n=8$, gray columns), or $75 \mathrm{mg} / \mathrm{kg}$ ( $n=13$, black columns). Values are mean \pm SEM; * $p<0.00833$ vs $\mathrm{Nj}$ PHZ $75 \mathrm{mg} / \mathrm{kg}$ controls; $\$ p<0.00833$ vs jj $0 \mathrm{mg} / \mathrm{kg}$ PHZ controls; $\mathbb{}[p<0.00833$ vs jj $25 \mathrm{mg} / \mathrm{kg}$ PHZ; $\$ p<0.00833$ vs jj $50 \mathrm{mg} / \mathrm{kg}$ PHZ by post hoc Tukey HSD tests. $A$, Interwave intervals I-II and I-III were significantly longer in the jj PHZ $75 \mathrm{mg} / \mathrm{kg}$ group than in controls. The I-III interwave interval increase is more notable because wave III was absent and was excluded from the analysis in the most severely affected animals (6 of 13 jjs in the PHZ 75 $\mathrm{mg} / \mathrm{kg}$ group). BAEP I-II IWI was significantly prolonged in the PHZ 50 $\mathrm{mg} / \mathrm{kg}$ jj group $v s$ both PHZ $0 \mathrm{mg} / \mathrm{kg} \mathrm{jj}$ and PHZ $75 \mathrm{mg} / \mathrm{kg} \mathrm{Nj}$ controls. $B$, The amplitudes of II and III were decreased in the PHZ $75 \mathrm{mg} / \mathrm{kg}$ jj group $v s$ both the $\mathrm{jj}$ and $\mathrm{Nj}$ controls. For analyzing amplitudes, absent wave III values were scored as $0 \mu \mathrm{V}$ and included in the analysis. Note the significant decreases of amplitudes of all waves of the jj PHZ $75 \mathrm{mg} / \mathrm{kg}$ group $v s$ the $\mathrm{Nj}$ PHZ $75 \mathrm{mg} / \mathrm{kg}$ controls, decreased wave II and III amplitudes of jj PHZ $75 \mathrm{mg} / \mathrm{kg} v s$ the $\mathrm{jj}$ controls, and a progression of decreased amplitude of amplitude with PHZ dose in jjs.

rotoxicity causes severe physiologic changes such as fluid overload and/or alkalosis. Animal models that infuse i.v. bilirubin do not produce the characteristic clinical or neuropathological features of kernicterus. Only jaundiced (jj) Gunn rats and a premature Rhesus monkey given bilirubin have 
shown the characteristic electrophysiological abnormalities of bilirubin neurotoxicity $(8,14,18,19)$. In both models, neurologic disorders are produced or exacerbated by administration of a sulfonamide, which displaces bilirubin from blood albumin allowing its entry into the tissues $(6-8,20)$ producing many of the same sequelae observed in human kernicterus and BIND (5-7).

In this report, we demonstrate that inducing hemolysis with PHZ in the jj Gunn rat pup significantly elevates blood bilirubin levels in jjs and in $\mathrm{Njs}$, though to a much lower level in the latter. This results in central auditory processing abnormalities as assessed with BAEPs in jjs but not Njs. PHZ generated the highest TB levels we have ever observed in Gunn rats. The high TBs obtained in rats correspond to even higher TBs in humans because bilirubin does not bind as well to rat albumin as it does to human albumin $(21,22)$.

The BAEP abnormalities we observed are similar to those seen in the classic jj Gunn rat model of bilirubin-induced neurologic abnormalities achieved by using sulfadimethoxine $(6-8,20)$. These abnormalities are similar to BAEP abnormalities seen in humans with excessive hyperbilirubinemia and kernicterus (23-25). In addition, we observed a dose response effect of PHZ. The $75 \mathrm{mg} / \mathrm{kg}$ PHZ dose produced the most profound BAEP changes, mimicking the changes observed in jjs with sulfa administration, whereas the BAEP changes with lower doses (50 and $25 \mathrm{mg} / \mathrm{kg}$ ) were intermediate and not statistically significantly different from the control group. As we typically observe in sulfa treated jj animals, the PHZ 75 $\mathrm{mg} / \mathrm{kg}$ dose produced increased latencies of waves II and III, increased I-II and I-III IWIs, and decreased amplitudes of waves II and III in jjs. Anecdotally, we observed another effect of PHZ-induced hyperbilirubinemia, dystonia, a hallmark feature of kernicterus in humans (26).

Hemolytic anemia from PHZ treatment is believed to result from destabilization of $\mathrm{Hb}$ by the binding of a ligand derived from the aryl portion of PHZ (13). Exposure of erythrocytes to PHZ results in the degradation of both monomers of spectrin, a major cytoskeleton membrane protein (27). These results implicated oxidation products of $\mathrm{PHZ}$ and not proteolytic degradation as major contributors to PHZ-induced protein damage in red blood cells ghosts (28). PHZ directly oxidizes $\mathrm{Hb}$ and has a propensity to exacerbate G6PD deficiency and the precipitation of unstable hemoglobins (13). Hemolysis induced by PHZ has been used recently to increase bilirubin production in mice and investigate the role of MRP1 mediated ATP-dependent cellular extrusion of unconjugated bilirubin (29), and microarray technology has suggested potential biomarkers for PHZ-induced hemolytic anemia (30).

PHZ might produce BAEP abnormalities by mechanisms other than increasing plasma bilirubin levels. Anemia has been shown to lead to abnormal BAEPs $(31,32)$. In sheep with phlebotomy-induced anemia, BAEP wave latencies increased with increasing anemia and decreased following transfusion (32). However, the increased latency of wave I they reported affected peripheral auditory function, i.e. auditory nerve function, in contrast with our present study with PHZ and past studies in untreated $(14,19)$ and sulfonamide-treated jjs $(8,33,34)$ (Ahlfors et al., Brainstem auditory evoked potentials and bilirubin-albumin binding in Gunn rat pups, American Federation for Medical Research, Western section annual meetings. Carmel, California, February 1997) in which central function, I-II and I-III IWIs, and amplitudes of waves II and III, were primarily affected. Furthermore, the severity of the anemia, dropping hematocrit from about $35 \%$ to about $14 \%$, was much greater in the sheep than in our study. BAEPs in 4-y-old children who had iron deficiency in infancy have increased III-V and I-V IWIs reflecting increased central (brainstem) conduction time but no changes in wave amplitudes or peripheral (wave I) function (31), suggesting that iron deficiency anemia could affect myelination. In rats, BAEP waves I, II, and III correspond to human waves I, III, and V. Rat I-II and human I-III IWIs correspond to conduction time from the auditory nerve to the cochlear nucleus in the pons, whereas rat II-III and human III-V correspond to brainstem conduction time between the cochlear nucleus and lateral lemniscus (pons to midbrain). Our current PHZ data and our previous BAEP data in untreated and sulfonamide-treated jj Gunn rats suggest that bilirubin neurotoxicity selectively affects conduction between the auditory nerve and pons, and differs from the more rostral abnormality reported in formerly iron-deficient children (31). Furthermore, in both our PHZ and sulfonamide models we see decreased amplitudes of BAEP waves II and III, not seen in the phlebotomy-induced or iron deficiency anemia studies.

Finally, and most importantly, $\mathrm{Nj}$ animals given PHZ 75 $\mathrm{mg} / \mathrm{kg}$ experienced the same degree of anemia (Table 1) as the jjs, but had no BAEP abnormalities (Fig. $3 A$ and $B$ ) indicating the anemia was not likely producing the BAEP abnormalities in our model. Mejia et al. (35) recently characterized acutely induced anemia and hyperbilirubinemia in 7-d-old Sprague Dawley rat pups who received two doses of PHZ $75 \mathrm{mg} / \mathrm{kg}$, and suggested that the released iron ions may be a contributing factor to bilirubin encephalopathy. These studies obtained a TB of $5 \mathrm{mg} / \mathrm{dL}$, more than three times what we achieved in 15to 16 -d-old Njs $(1.5 \mathrm{mg} / \mathrm{dL})$ given a single $75 \mathrm{mg} / \mathrm{kg}$ injection. Additionally, Mejia et al. observed neuronal abnormalities including iron deposits predominantly in cortex, and some in hippocampus and hypothalamus. However, no electrophysiology was performed in these animals, and from our extensive experience in Gunn rats, it is unlikely that BAEP abnormalities would have been detected at those TB levels. Finally, Mejia et al. reported neither histologic abnormalities in the cerebellum, which is affected by bilirubin in Gunn rats at $7 \mathrm{~d}$ of age (5,36-39), nor abnormalities in the auditory brainstem. We have demonstrated histopathological abnormalities in the cerebellum (39) and auditory brainstem (40) of sulfa treated Gunn rats, and have preliminary data demonstrating TUNEL staining in the inferior colliculus $(41,42)$. Future studies will examine histologic changes following PHZ treatment.

PHZ might also have direct yet unknown brain effects. It might also cause BAEP abnormalities by directly displacing bilirubin from albumin, or by producing free radicals, which have been shown to degrade serum albumin (28) and spectrin $(27,28)$, and could result in increased free bilirubin. However, these are unlikely because the TB levels in blood rose dramatically, and when bilirubin is not bound to albumin, it exits 
the blood stream almost completely within half an hour (15). However, some displacement cannot be excluded, and studying the evolution of the unbound and total bilirubin after PHZ may be a worthwhile future study. Finally, it is also possible that PHZ will act to produce acidosis, which we did not assess in our animals, and which may have resulted in BAEP abnormalities. Significant acidosis would likely exacerbate bilirubin neurotoxicity and BAEP abnormalities. The interactions of TB and $\mathrm{pH}$, if they occur in this model, would be similar and thus relevant to clinical situations in some neonates.

Using PHZ to produce hyperbilirubinemia in Gunn rats may be more clinically relevant than the sulfadimethoxine displacer model. In this model, one can correlate TB, free bilirubin, and bilirubin albumin binding with measures of CNS damage. This model can be used to study varying levels of abnormality, which can be better quantified by measuring $\mathrm{TB}$, and can be used to produce acute bilirubin encephalopathy in younger and older animals to address the research question of whether there is a neurodevelopmental sensitivity to bilirubin neurotoxicity. Finally, this model of PHZ-induced hemolysis in $\mathrm{jj}$ Gunn rats enables us to relate hemolysisinduced hyperbilirubinemia to clinical symptoms and neurologic dysfunction and to better model human kernicterus and hyperbilirubinemia, though it is also possible that PHZ might have direct yet unknown brain effects.

Acknowledgments. We thank Drs. Claudio Tiribelli, J. Donald Ostrow, and Dean Cekic for suggesting the use of PHZ in our model.

\section{REFERENCES}

1. Stevenson DK, Fanaroff AA, Maisels MJ, Young BW, Wong RJ, Vreman HJ, MacMahon JR, Yeung CY, Seidman DS, Gale R, Oh W, Bhutani VK, Johnson LH, Kaplan M, Hammerman C, Nakamura H 2001 Prediction of hyperbilirubinemia in near-term and term infants. Pediatrics 108:31-39

2. Strebel L, Odell GB 1971 Bilirubin uridine disphosphoglucuronyltransferase in rat liver microsomes: genetic variation and maturation. Pediatr Res 5:548-559

3. Maisels MJ 2006 Neonatal jaundice. Pediatr Rev 27:443-454

4. Gunn CH 1938 Hereditary acholuric jaundice in a new mutant strain of rats. J Hered 29:137-139

5. Schutta HS, Johnson L 1969 Clinical signs and morphologic abnormalities in Gunn rats treated with sulfadimethoxine. J Pediatr 75:1070-1079

6. Blanc WA, Johnson L 1959 Studies on kernicterus; relationship with sulfonamide intoxication, report on kernicterus in rats with glucuronyl transferase deficiency and review of pathogenesis. J Neuropathol Exp Neurol 18:165-189

7. Rose AL, Wisniewski H 1979 Acute bilirubin encephalopathy induced with sulfadimethoxine in Gunn rats. J Neuropathol Exp Neurol 38:152-165

8. Shapiro SM 1988 Acute brainstem auditory evoked potential abnormalities in jaundiced Gunn rats given sulfonamide. Pediatr Res 23:306-310

9. Shaia WT, Shapiro SM, Spencer RF 2005 The jaundiced Gunn rat model of auditory neuropathy/dyssynchrony. Laryngoscope 115:2167-2173

10. Shapiro SM 2003 Bilirubin toxicity in the developing nervous system. Pediatr Neurol 29:410-421

11. Andersen DH, Blanc WA, Crozier DN, Silverman WA 1956 A difference in mortality rate and incidence of kernicterus among premature infants allotted to two prophylactic antibacterial regimens. Pediatrics 18:614-625
12. Jardine DS, Rogers K 1989 Relationship of benzyl alcohol to kernicterus, intraventricular hemorrhage, and mortality in preterm infants. Pediatrics 83:153-160

13. Itano HA, Hosokawa K, Hirota K 1976 Induction of haemolytic anaemia by substituted phenylhydrazines. Br J Haematol 32:99-104

14. Shapiro SM, Hecox KE 1989 Brain stem auditory evoked potentials in jaundiced Gunn rats. Ann Otol Rhinol Laryngol 98:308-317

15. Rice AC, Shapiro SM 2006 Biliverdin-induced brainstem auditory evoked potential abnormalities in the jaundiced Gunn rat. Brain Res 1107:215-221

16. Keppel G 1982 Design and Analysis: A Researcher's Handbook. Prentice-Hall, Englewood Cliffs, New Jersey, p 669

17. Lagakos SW 2006 The challenge of subgroup analyses-reporting without distorting. N Engl J Med 354:1667-1669

18. Ahlfors CE, Bennett SH, Shoemaker CT, Ellis WG, Davis SL, Wennberg RP, Goetzman BW 1986 Changes in the auditory brainstem response associated with intravenous infusion of unconjugated bilirubin into infant rhesus monkeys. Pediatr Res 20:511-515

19. Shapiro SM, Hecox KE 1988 Developmental studies of brainstem auditory evoked potentials in jaundiced Gunn rats. Brain Res 469:147-157

20. Shapiro SM, Conlee JW 1991 Brainstem auditory evoked potentials correlate with morphological changes in Gunn rat pups. Hear Res 57:16-22

21. Brodersen R 1980 Binding of bilirubin to albumin. CRC Crit Rev Clin Lab Sci 11:305-399

22. Ahlfors CE, Shapiro SM 2001 Auditory brainstem response and unbound bilirubin in jaundiced (ij) Gunn rat pups. Biol Neonate 80:158-162

23. Wennberg RP, Ahlfors CE, Bickers R, McMurtry CA, Shetter JL 1982 Abnormal auditory brainstem response in a newborn infant with hyperbilirubinemia: improvement with exchange transfusion. J Pediatr 100:624-626

24. Nwaesei CG, Van Aerde J, Boyden M, Perlman M 1984 Changes in auditory brainstem responses in hyperbilirubinemic infants before and after exchange transfusion. Pediatrics 74:800-803

25. Amin SB, Ahlfors C, Orlando MS, Dalzell LE, Merle KS, Guillet R 2001 Bilirubin and serial auditory brainstem responses in premature infants. Pediatrics 107:664-670

26. Shapiro SM 2005 Definition of the clinical spectrum of kernicterus and bilirubininduced neurologic dysfunction (BIND). J Perinatol 25:54-59

27. Arduini A, Storto S, Belfiglio M, Scurti R, Mancinelli G, Federici G 1989 Mechanism of spectrin degradation induced by phenylhydrazine in intact human erythrocytes. Biochim Biophys Acta 979:1-6

28. Chakrabarti S, Naik AA, Reddy GR 1990 Phenylhydrazine mediated degradation of bovine serum albumin and membrane proteins of human erythrocytes. Biochim Biophys Acta 1028:89-94

29. Cekic D, Bellarosa C, Garcia-Mediavilla MV, Rigato I, Pascolo L, Ostrow JD, Tiribelli C 2003 Upregulation in the expression of multidrug resistance protein Mrp1 mRNA and protein by increased bilirubin production in rat. Biochem Biophys Res Commun 311:891-896

30. Rokushima M, Omi K, Araki A, Kyokawa Y, Furukawa N, Itoh F, Imura K Takeuchi K, Okada M, Kato I, Ishizaki J 2007 A toxicogenomic approach revealed hepatic gene expression changes mechanistically linked to drug-induced hemolytic anemia. Toxicol Sci 95:474-484

31. Algarin C, Peirano P, Garrido M, Pizarro F, Lozoff B 2003 Iron deficiency anemia in infancy: long-lasting effects on auditory and visual system functioning. Pediatr Res 53:217-223

32. Quinonez RE, Widness JA 2003 Increased wave latency in auditory brainstem response to anemia in newborn and adult sheep. Biol Neonate 84:179-186

33. Shapiro SM 1993 Reversible brainstem auditory evoked potential abnormalities in jaundiced Gunn rats given sulfonamide. Pediatr Res 34:629-633

34. Shapiro SM 2002 Somatosensory and brainstem auditory evoked potentials in the Gunn rat model of acute bilirubin neurotoxicity. Pediatr Res 52:844-849

35. Mejia GB, Sanz CR, Avila MM, Peraza AV, Guzman DC, Olguin HJ, Ramirez AM Cruz EG 2008 Experimental hemolysis model to study bilirubin encephalopathy in rat brain. J Neurosci Methods 168:35-41

36. Schutta HS, Johnson L 1967 Bilirubin encephalopathy in the Gunn rat. A fine structure study of the cerebellar cortex. J Neuropathol Exp Neurol 26:377-396

37. Aono S, Semba R, Sato H, Kashiwamata S 1989 Mode of bilirubin deposition in the cerebellum of developing jaundiced Gunn rats. Biol Neonate 55:119-123

38. Keino H, Kashiwamata S 1989 Critical period of bilirubin-induced cerebellar hypoplasia in a new Sprague-Dawley strain of jaundiced Gunn rats. Neurosci Res 6:209-215

39. Conlee JW, Shapiro SM 1997 Development of cerebellar hypoplasia in jaundiced Gunn rats treated with sulfadimethoxine: a quantitative light microscopic analysis. Acta Neuropathol 93:450-460

40. Conlee JW, Shapiro SM 1991 Morphological changes in the cochlear nucleus and nucleus of the trapezoid body in Gunn rat pups. Hear Res 57:23-30 